\title{
Research on College English Task-based Teaching Model from the Perspective of Construction Theory
}

\author{
Xichun Dong \\ Xijing University, Xi’an, Shaanxi, 710123
}

Keywords: Task-based Teaching Model, Construction Theory, College English

\begin{abstract}
Constructivism argues that knowledge is not passed by teachers, but rather that learners use the necessary learning materials, with the help of others, including teachers and learning partners, through learning in the context of social and cultural context, through the construction of the meaning of the way. Task-based teaching is a way of teaching students to learn from the problems or tasks in the subject area, through various forms of activities, to acquire knowledge and skills, to cultivate inquiry ability and application ability, and to obtain emotional experience. This paper explores several schemes in the task-based teaching of Chinese and English and the possible problems in the process of implementation.
\end{abstract}

\section{Introduction}

Based on the constructivist English task - based teaching method is a different from the traditional teaching model. This model not only emphasizes the language form, but also focuses on its meaning and function, both to emphasize the necessary language form system, but also learn to use these language forms system to complete the communication task, with strong operability. Task-based teaching is a kind of language teaching mode which has been influenced by foreign language teaching researchers in the 1980s. It has transformed the basic idea of language application into practical classroom teaching method. Students under the guidance of teachers, through the perception, experience, practice, participation and cooperation, etc., to achieve the objectives of the task, feel successful. In the learning process of emotional and strategic adjustments form a positive attitude to learn to promote the practical use of language ability. Task-based teaching requires the creative design of teachers and the students' actual life phenomenon, attracting and organizing their active participation. Students learn and use English to complete their learning tasks through thinking, investigation, discussion, communication and cooperation. Based on the theory of constructivism, this paper explores the feasible teaching model of student - centered English task - based teaching in college English teaching.

\section{Constructivism Theory}

Constructivism, also known as structuralism, is proposed by the famous Swiss psychologist Piaget. This theory is derived from the theory of children's cognitive development, individual cognitive development and learning process is closely related. Constructivists generally emphasize that knowledge is only an explanation, a hypothesis that it is not the final answer to the question, it will continue to be "revolution" with the progress of mankind, and the emergence of new assumptions; knowledge and cannot accurately sum up the rules of the world, in specific issues need to re-create for specific situations; knowledge cannot exist in the form of entities outside the specific individual. The use of constructivism can better explain the cognitive process of human learning process. Constructivism believes that knowledge is not taught by teachers, but learners in a certain situation that is social and cultural background, with the help of others, using the necessary learning materials, through the meaning of the construction approach.

The theory of constructivism suggests that it advocates learner-centered learning under the guidance of teachers, that is, not only emphasizes the learner's cognitive subject function, but also 
ignores the teacher's guiding role and the teacher is the help of meaning construction and the facilitator, not the communicator of the knowledge and the inculcator. Students are the subject of information processing, the active constructor of the meaning, rather than the passive stimulator of the external stimulus and the instilled object. This method puts forward the following two requirements to the students: First, in the construction of the meaning of the process requires students to take the initiative to collect and analyze the relevant information and information on the learning issues to put forward various assumptions and efforts to be verified. Second, the current learning content should be reflected in the contents of the existing knowledge associated with the timely extraction of information already in the brain, and this link to seriously think about. In order to effectively use this method, teachers should try to stimulate students' interest in learning, help students to form learning motivation, in the possible conditions of collaborative learning (to discuss and exchange), and collaborative learning process to guide. The methods of guidance include: raising appropriate questions to raise students 'thinking and discussion; trying to deepen the problem in order to deepen the students' understanding of what they have learned in the discussion; to inspire students to discover their own rules and to correct themselves and supplement the wrong or one-sided understanding. Through the creation of meet the requirements of the teaching content of the situation and prompted the link between old and new knowledge of the clues to help students build the meaning of the current knowledge.

\section{Basic Characteristics of Task - based Approach}

Task - based teaching method is based on constructivism. The basic characteristics of task-based teaching are to "task" as the core unit planning, organization of teaching. Tasks in task-based learning are not general, isolated, or any combination of in-class or extra-curricular teaching or learning activities, but an integral part of the whole system (or course). The form of the task is to use language to deal with simulated or real life problems; the effective integration of all aspects of the task and the interaction points to the overall goal of the course. Students consciously strengthen and select relevant learning strategies, including selective listening, reading, scanning, classification, strengthening, practice, memory, review and so on. It is through the implementation of the task and participation activities, to promote their own knowledge of the "reorganization" and "build", once the students experience the meaning of participation in activities, feel the success of new knowledge construction, they will be more active and positive, thus accelerating knowledge of internalization.

\section{A Probe into College English Task - based Teaching}

Teachers in the teaching of the new lesson before the arrangement of students make a preview session, self-preview text content, to understand the effect of the text. And then let the students themselves to the main content of the text to write out, summary mainly include the text and their views or comments. And then each time class, with a lesson around the time, first by different students to represent, dialogue or role-playing, and then let all the other teachers and students with the comments, after each round, the teacher of the group of students to score, And write reviews. In this kind of oral training, in addition to improving students' ability of autonomous learning, reading comprehension and writing ability, but also to improve student interest in learning, to mobilize the enthusiasm and initiative of the students, team collaboration and cooperation has been strengthened.

In the teaching process emphasizes interactive learning. The traditional text teaching is teacher-centered, students listen and take notes, students are passive, is the inculcation of knowledge objects, failed to reflect the initiative and enthusiasm of students. I believe that the task of explaining the text can be part of the students to complete. For example, the text is divided into sections, so that students to explain, teachers in the process of teaching students to properly encourage and help students, and then teachers of new knowledge and students to teach the contents of the summary, correction and supplement. This can greatly stimulate the enthusiasm of students to learn, to avoid the students to sleep or attention to the phenomenon of concentration. And students through the "lesson preparation", "teaching" this process, the ability of students to improve, 
teaching efficiency has also been greatly improved.

Teachers can be based on teaching content or some of the current social phenomena and issues agreed to a debate, the class can be divided into square and anti-side, arranged in advance to the students, students in the form of group division, the use of spare time to collect the contents of the topic to prepare the debate material. And then carry out a debate on the race, the teacher as the role of the judge, the classroom organization, students in the debate process, teachers should promptly correct some of the grammar or lexical errors, and then let the students to the best debater. So the classroom atmosphere is very active, and cultivates the students for the organization and expression of English, but also cultivate the ability of students to speak.

Under the guidance of constructivism, English writing teaching focuses on the construction of meaning, focusing on the process of writing, focusing on collective writing tasks, focusing on the interaction between students and many times, focusing on the interaction between teachers and students. In this teaching process, teachers should organize as much as possible collaborative learning, to discuss and exchange, and to guide the process of collaborative learning to make it conducive to the direction of the construction of meaning, in the specific teaching practice will be the basis of writing teaching process can be divided into pre-written, draft, mutual assessment, teacher evaluation, revision, the second assessment, the second teacher assessment of seven links. The whole process of writing is student-centered, emphasizing the interaction and consultation between students and teachers, students and peers, changing the monopoly role of former teachers, teachers in the writing process as organizers, coordinators, questioners and information providers to guide students to successfully complete the whole process of writing, to encourage students and their partners to learn more, and more consultation, and asked students to focus on writing content mining and expression, so that students actively into the writing process at all stages, give full play to students' subjective initiative, so that students really understand the essence and meaning of writing, so that students in the writing process of solid training, and constantly improve the writing ability. With particular emphasis on commentary feedback stage, comment feedback is the central stage of the writing process, which is between the first draft and the revision phase. This stage is indispensable to critical cognition and is necessary for students to perfect and reconstruct cognition. The traditional practice is the teacher's correction, the practice of large workload, time-consuming, coupled with the number of teachers with the number of students, some teachers often only give a score, or find a language error or draw a grammatical error, no can be from the structure or discourse on the deep-level correction, to inspire students to think, to help students enrich the content and improve the structure of the article, so take the same level of feedback or peer evaluation. Each time a student completes a preliminary draft, he will ask them to perform a specific review on the length of the article's content and language, etc., in accordance with the specific criteria and rules provided by the teacher in advance. Students are required to find out among the peer essays Flash point, and the students some good language expression and some of the expression of the defect or wrong place marked with a different logo, and finally for the strengths and weaknesses of the article to write specific comments. This kind of evaluation and feedback mode not only protects the students 'self-image, strengthens the students' writing confidence, but also greatly promotes the mutual learning among students, learns from each other, is advantageous to the improvement of writing ability. To shorten, teaching efficiency can be improved.

The Student-centered task-based teaching model has certain requirements for modern educational technology, requiring the number of students cannot be too much; the development of modern educational technology is also a problem of uneven regional development; colleges and universities generally exist in large class situation the Teachers to organize learning, discussion, collaboration, answering questions, timely guidance and so there are some difficulties. On the other hand, the quality of college students' own English acquisition cannot meet the requirements of constructivism teaching. Although they have a strong desire to learn English and want to get rid of the traditional way of learning, but the original way of objectivism is their habit of information input single cognitive form, to prevent their active participation and construction of learning ability. 
For a considerable number of teachers, the purpose of classroom teaching is not to help students develop self-learning ability, but to develop students' test skills. In addition, this teaching evaluation method also misled the students' English learning goals. Chinese students in English learning has a clear tendency to test, many college students in order to pass the 46 exam or college entrance examination, most of the time spent on the pro forma, the classroom has nothing to do with the contents of the examination do not want to listen, Wish to see the end of the exam, it means the end of their college English study. Therefore, the evaluation method of the examination tendency is not conducive to the divergence of students, the development of critical thinking; also cannot implement the constructivist advocacy in the learning process through reflection and self-evaluation of the formation of evaluation to achieve the goal of providing learners knowledge conversion ability.

\section{Conclusion}

The reform of college English teaching mode is the inevitable trend of the development of college English teaching. It is not only the change of teaching activities and means, but also the change of teaching idea. In this paper, the task-based teaching method under the guidance of the concept of constructivism education, you can use the task-based teaching methods to college English classroom teaching in all aspects. Student-centered, design and carry out a variety of learning activities to stimulate students to learn initiative, teachers as partners and organizers, this to improve students' ability to use English for the purpose of teaching model, will cultivate students interested in learning English, improve students Their own comprehensive quality, to achieve the meaning of language knowledge and ability to build a comprehensive development of the realm. Of course, the English task-based teaching method in the actual teaching of the various problems also need to be further discussed and resolved, teachers should continue to improve the practical teaching methods and methods.

\section{References}

[1] Wu Mengling. Application of Task-based Teaching Method in French Grammar Teaching[J]. Education Modernization. 2017 (32)

[2] Zhang Shuai. Task-based teaching method in college English classroom teaching application[J]. Western quality education. 2017 (16)

[3] Gao Dan. Application of task-based teaching method in garment English teaching [J]. Overseas English. 2017 (16)

[4] Yang Ruifang.Application of task-based teaching method in classroom teaching of English film and television appreciation in higher vocational colleges [J]. Journal of Luliang Education College. 2017 (02)

[5] Yang Xuyang. Task-based teaching method in college English teaching application analysis[J]. Talent. 2017 (22)

[6] Su Xuelian. Task-based teaching method in college English teaching application[J] .Liuliang Institute of Education. 2017 (02)

[7] Qi Yang. Task-based teaching method in private college business English teaching application[J]. Higher Education Journal 2017 (17) 